\title{
Bit-induced pain: a cause of fear, flight, fight and facial neuralgia in the horse
}

\author{
W. Robert Cook \\ School of Veterinary Medicine, Tufts University
}

\begin{abstract}
Summary
An ethological survey was based on 605 written reports from horsemen who had switched from a bitted bridle to a new bitless bridle. The comparison of equine behaviour was between an invasive and painful method of control (a bitted bridle) and a non-invasive and painless method (a bitless bridle). The unprecedented opportunity to switch a horse, overnight, from painful to painless control revealed many new and serious manifestations of the syndrome 'aversion to the bit.' The survey demonstrated that the bit method of control caused 58 adverse behavioral effects. All 58 effects could be classified under four major effects; to instill fear, to trigger flight, to make the horse fight back, and to cause facial neuralgia (the headshaking syndrome). These effects could all, in turn, be categorized as responses to oral pain. The sensory pathway for registering pain caused by the bit is the trigeminal nerve but the motor pathways involved many systems, with the nervous, respiratory and musculoskeletal systems predominating. The behavioral responses interfered, in particular, with attitude to exercise, breathing and locomotion. A survey of 65 horse skulls revealed painful, bit-induced exostoses on the mandibular diastema in 49 (75\%). It was concluded that a bit is harmful to the health and safety of horse and rider, and an impediment to performance.
\end{abstract}

Keywords: horse; bit; survey; pain; behavior; respiration; locomotion

\section{Durch das Gebiss induzierter Schmerz - Ursache für Angst, Fluchtverhalten, Widerstand und Facialisneuralgie beim Pferd}

Auf der Basis von 605 schriftlichen Berichten von Reitern, die vom konventionellen Gebiss auf eine gebisslose Zäumung ungestiegen sind, bilden die Grundlage einer Übersicht über dadurch bedingte Verhaltensänderungen der Pferde. Zuerst war die invasive und schmerzhafte Zäumung mit Gebiss gegeben, dann die nicht invasive, schmerzfreie Zäumung ohne Gebiss. Der unmitelbare Wechsel, quasi über Nacht, von einer schmerzhaften zu einer schmerzfreien reiterlichen Kontrolle legte mancherlei ernste Auswirkungen des Syndroms "Gebissaversion" an den Tag. Die Untersuchung ergab 58 unterschiedliche, durch das Gebiss verursachte negative Auswirkungen auf das Verhalten, die in vier Gruppen eingeteilt werden konnten: Angst, Fluchtverhalten, Widerstand und Facialisneuralgie (Headshaking). All diese Auswirkungen können als Antwort auf oralen Schmerz gewertet werden. Die sensorische Leitung der durch das Gebiss verursachten Schmerzen geschieht über den N. trigeminus, in die motorische Leitung sind jedoch viele verschiedene anatomische Strukturen involviert, wobei Nervensystem, Atmungs- und Bewegungsapparat im Vordergrund stehen. Die durch das Gebiss ausgelösten Verhaltensänderungen beeinflussen teilweise die Leistung, die Atmung und die Bewegung. Die Untersuchung von 65 Pferdeschädeln zeigte in 49 Fällen (75\%) Gebiss-induzierte Exostosen im Bereich des mandibulären Diastema. Insgesamt lässt sich der Schluss ziehen, dass das Gebiss für die Gesundheit des Pferdes und die Sicherheit des Reiters schädlich ist und die Leistungsfähigkeit des Pferdes behindert.

Schlüsselwörter: Gebiss, Schmerz, Verhalten, Atmung, Bewegung, Leistung, Tierschutz, headshaking

\section{Introduction}

In the last six years, a new design of bitless bridle (The Bitless Bridle) has been introduced. The bridle can be used by riders of all ages and experience, for all equestrian disciplines, and on horses of all breeds, types, and temperaments. Because there is little or no learning curve for either horse or rider, a horse can be switched instantly from bit to bitless control, so providing an unprecedented opportunity to identify the bit's adverse effect on behaviour.

The bit is an invasive method of control and painful, whereas the bitless bridle is non-invasive and painless (Cook 1999, $2000,2002)$. Whereas the bit method of control is incompatible with the physiological requirements of an exercising horse, the bitless method is compatible (Cook 1999). Because of this there is usually a marked contrast in the behaviour of a horse when the two methods are compared. The opportunity to dispense with the bit, overnight, in a large series of horses that had previously worn a bit for many years, has shown that we have underestimated the frequency and diversity of the adverse effects on behaviour attributable to the bit method of control. If asked to compile a list of the problems included in the term 'aversion to the bit,' most horsemen would probably cite about six problems. This study has shown that the actual number of problems is over 60 (Table I). The purpose of this article is to document this information.

There are many similarities between the properties of reflexes and complex behaviour (Manning 1979). The stimulus for the complex behaviour patterns caused by the bit is pain. The sensory pathway is clearly the trigeminal nerve. But the motor pathways are many and complex. The largest category of adverse behavioral effects associated with use of the bit can be assigned to changes of a horse's attitude to exercise (column N, Table 1). But evidence indicates that the pressure a rider (or driver) exerts on one or more bits in the highly sensitive oral cavity interferes with all the major systems of the body except the reproductive system (Cook 2000). The three systems that are most obviously affected are the nervous, respiratory and musculoskeletal systems. So in addition to changes of attitude, we find evidence of interference with breathing and locomotion. 
The anatomical and physiological explanations for the respiratory and musculoskeletal effects of the bit have already been described (Cook 1999, 2000, 2002). This study focuses on the ethological aspects of the subject.

\section{Materials and Methods}

A list of the adverse behavioural signs that have disappeared following removal of the bit were compiled from the written and unsolicited reports received from users of the new bitless bridle (See Users' Comments online at www.bitlessbridle. com). The reports from 605 users were collected over a period of six years from 1997-2002. Many users described their experience with more than one horse, so the reports actually represented observations on over 700 horses. Reports varied in length from a couple of paragraphs to several pages. In many instances, owners submitted several reports on the same horse. These were counted as one report. The total col-
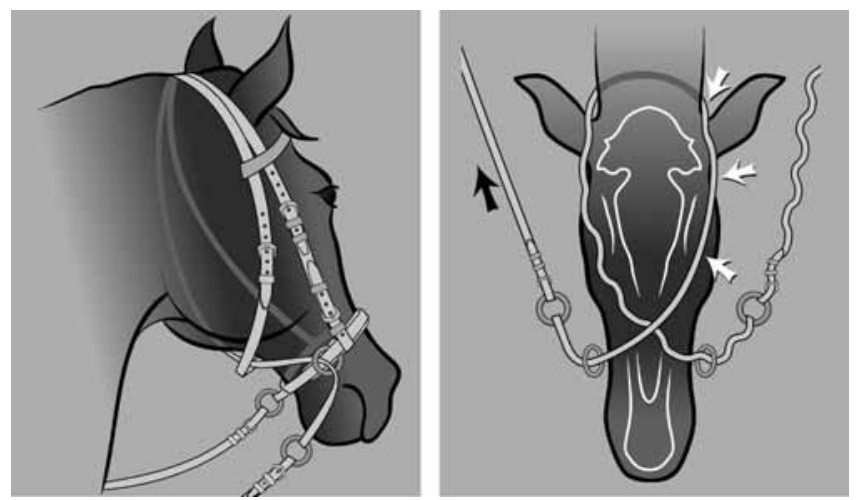

Fig 1 Action of The Bitless Bridle: Pressure on one rein (black arrow) pushes painlessly on the entire contralateral half of the head (at white arrows, noseband and chinstrap), signaling a turn. Pressure on both reins hugs the whole of the head, signaling a halt.

Wirkprinzipg des gebisslosen Reithalfters. Der Zug an einem Zügel (schwarzer Pfeil) übt schmerzfreien Druck auf die gesamte kontralaterale Kopfhälfte aus (weiße Pfeile: Nasenund Kinnriemen) und signalisiert Wendung. Zug auf beide Zügel löst Druck auf den ganzen Kopf aus und signalisiert Parade.

lection, which constitutes a clinician's 'laboratory notebook', comprises a text of 184.000 words. The notebook is available online, where the reports have been sorted according to discipline, breed and, to a limited extent, by clinical signs (specifically, the headshaking syndrome and abnormal respiratory noise at exercise). Both positive and negative feedback was documented. The few negative reports have been highlighted in red for easier location.

Most riding disciplines were represented. Numerically, the collection is considered to be reasonably representative of the domestic horse population in North America. There were also reports from Europe and Australasia. Horses placed in a category of 'general equitation' accounted for 278 (46\%), 'trail riding and endurance' accounted for 165 (27\%) and, collectively, the remaining disciplines accounted for 162 (27\%). The latter category includes only five reports from carriage-drivers, so the majority of reports relate to riding. The actual bits removed have covered the spectrum of designs from snaffle to leverage bits.

As an old medical adage states that nothing ruins results more than long-term follow-up, one section of the online notebook is compiled of multiple reports from the same person over an extended period of time. These might, for example, consist of seven reports about the same horse over a period of twelve months.

As the reports were unsolicited they do not follow a standard format. The advantage of this has been that each owner has selected those changes that they personally consider to be the most remarkable and most important. Because there is no standard terminology for equine behavior, the author has frequently resorted to using the exact words and phrases used by the owner. Vernacular language is unusual in a scientific article but considered necessary here in the interest of communication. Descriptive terms being imprecise, there is - inevitably - some overlapping of terms. A list of problems was compiled, in order of frequency of occurrence, and classified according to the category under which they can be said to exert their primary effects (Table I).

On a few occasions, the written reports have been accompanied by video film evidence, showing a horse's behavior when ridden with and without a bit.

Supplementary evidence came from a survey of adult Equidae skulls in the collections of three Natural History Museums.

\section{Results}

Survey of reports

From a total of 605 reports there were 19 negative reports (3\%). This percentage is lower than that which one might expect, simply as a result of human error when using a new piece of equipment. In the author's experience, a failure on the part of the rider to fit and use the bridle correctly has generally been the explanation for a 'failure' of the method. The remaining 586 reports were positive. The naked number fails to tell the whole story. Riders, as a group, expressed tremendous enthusiasm for the new method of control. The behavioral signs reported as having been eliminated when the bit was removed are listed according to the frequency with which each sign was cited (Table I). It was found that there

Tab 1 Showing the number of times that a particular item of adverse behaviour was cited in 586 reports as having being eliminated by replacing a bitted bridle with a bitless bridle. Showing also the main bodily systems affected. Line items $1-4$ are in bold type as line items $5-58$ are really subsets of one or more of the first four. Key: DDSP $=$ dorsal displacement of the soft palate. $M / S=$ musculoskeletal system. $N=$ nervous system. $R=$ respiratory system. ${ }^{*}=$ signs considered part of the headshaking syndrome. $(\# \ldots)=$ see also the line item referenced. Art und Häufigkeiten sowie zugeordnete funktionelle Bereiche einzelner negativer Verhaltensbesonderheiten, die entsprechend der Auswertung von 586 Erfahrungsberichten durch Ersetzen eines konventionellen Gebisses durch das gebisslose Reithalfter eliminiert wurden. Punkte 1-4 (fett): übergeordnete Verhaltens- bzw. Syndromleitgruppen. Punkte 5-58: Unterpunkte zu einer oder meherer der 4 übergeordneten Leitgruppen. Abkürzungen: DDSP = Dorsalverlagerung des weichen Gaumens, M/S = Bewegungsapparat, $N=$ Nervensystem, $R=$ Atmungsapparat, ${ }^{*}=$ Anzeichen, die dem Headshaking-Syndrom zugeordnet werden, \# = siehe auch die genannte Leitgruppe. 


\begin{tabular}{|c|c|c|c|c|c|}
\hline \multirow[t]{2}{*}{ Item } & \multirow{2}{*}{$\begin{array}{l}\text { ADVERSE BEHAVIOUR (OR CLINICAL SIGN) ELIMINATED } \\
\text { BY REMOVAL OF THE BIT AND USE OF THE BITLESS BRIDLE }\end{array}$} & \multirow{2}{*}{$\begin{array}{c}\# \\
\text { cited }\end{array}$} & \multicolumn{3}{|c|}{ SYSTEM } \\
\hline & & & $\mathbf{N}$ & $\mathbf{R}$ & M/S \\
\hline 1 & FEAR: Anxious, unpredictable, nervous, frightened, shy, spooky, panicky, tense, stressed & 90 & + & + & + \\
\hline 2 & FLIGHT: Difficult to slow or stop, bolting, rushing the jumps & 75 & + & & + \\
\hline 3 & FIGHT: Argumentative, confrontational, resistant, aggressive, bossy, cranky, surly & 70 & + & + & + \\
\hline 4 & FACIAL NEURALGIA: Headshaking, head tossing or flipping (\#'s $36,39,40,45)^{*}$ & 66 & + & + & + \\
\hline 5 & Hates the bit, chomping, teeth grinding, fussing with the bit, evading contact (\#15) & 41 & + & + & + \\
\hline 6 & Difficult to bridle, holds head high, panics at the very sight of a bridle, breaks out in a sweat & 41 & + & & \\
\hline 7 & Above the bit (poking nose in the air), high-headed, „braced”, avoiding the bit & 34 & + & & + \\
\hline 8 & Difficult to steer in one or both directions, lugging in or out on the racetrack, inability to travel straight & 32 & + & & + \\
\hline 9 & Lack of finesse in control, anxious expression, general „unhappiness” when exercised & 30 & + & & \\
\hline 10 & Stiff-necked and locked-jaw (often with tongue over bit), reluctant to flex at the poll & 29 & + & & + \\
\hline 11 & Lack of self-carriage, absence of „collection”, poor balance, unable to be put in a frame (\#30) & 28 & + & & + \\
\hline 12 & Heavy on the forehand, leaning on the bit, tongue over the bit, low-headed & 25 & + & & + \\
\hline 13 & Tongue behind the bit, „thick-winded', roaring, DDSP, gurgling (choking-up), laryngeal stridor & 25 & + & + & \\
\hline 14 & Incoordination. Stiff or choppy stride („bridle lameness”). Short stride giving slower speed & 22 & + & & + \\
\hline 15 & Gaping of the mouth (open mouth), constant jaw and tongue movement (\#5) & 20 & + & + & \\
\hline 16 & Pulling on the bit, especially when heading home, pounds of rein pressure needed rather than ounces & 17 & + & & \\
\hline 17 & Lacking in courage or confidence, not „forward”, refuses at jumps, lacking hind-end impulsion & 16 & + & & + \\
\hline 18 & Lazy, dull, tires prematurely, lack of life force, subdued, ring sour, need for spurs & 16 & + & & + \\
\hline 19 & Behind the bit; overbent, over-flexed. Contributes to \& sometimes accompanied by items in \#13 & 12 & + & + & \\
\hline 20 & Jigging, prancing, and „rushing” when required to walk & 12 & + & & + \\
\hline 21 & Unfocussed, fussy, fidgety. Horse thinking of its painful mouth rather than where it is going & 12 & + & & \\
\hline 22 & Refusal to back-up or difficulty in backing-up. Inability to rein back in a straight line & 11 & + & & + \\
\hline 23 & Tilts head at exercise or refuses to keep head facing the line of travel. Accompanied by twisting of neck & 11 & + & & + \\
\hline 24 & Salivating excessively. Froths at mouth, drooling and slobbering & 11 & + & + & \\
\hline 25 & Bucking, sometimes accompanied by spinning & 10 & + & & + \\
\hline 26 & Sweating excessively, hot and restless at exercise, „lathering-up" & 10 & + & & \\
\hline 27 & Lack of progress or slow progress in response to training („stagnation”) & 10 & + & & \\
\hline 28 & Rearing, with or without flipping over backwards (somersaulting). Potentially fatal to horse and rider & 9 & + & & + \\
\hline 29 & Stumbling. This often accompanied by sluggishness \& loss of interest in work (\#18) & 8 & + & & + \\
\hline 30 & Inverted frame (high head carriage, hollow back), „strung-out”, (\#11) & 8 & + & & + \\
\hline 31 & Pig-rooting (,gagging” and „yawing”), diving with head and snatching the reins out of the riders hands & 8 & + & & + \\
\hline 32 & Tongue lolling, tongue protrusion & 8 & + & & \\
\hline 33 & Hair-trigger response to the aids, hypersensitivity to the bit & 7 & + & & + \\
\hline 34 & Difficult to mount, fidgety, tense (neck braced,ears pinned), moves away prematurely & 5 & + & & + \\
\hline 35 & Coughing at the start of exercise & 4 & + & + & \\
\hline 36 & Rubbing muzzle or face on fore-leg, at \& after exercise, striking at muzzle with fore leg during exercise* & 4 & + & & + \\
\hline 37 & Yawning during bridling (often accompanied by head tossing), and yawning during or after exercise & 4 & + & & \\
\hline 38 & During endurance rides, refusal or reluctance to eat and/or drink adequately & 3 & + & & \\
\hline 39 & Grazing on the fly' (eating on the run), grabbing at grass or snatching at the leaves of trees in passing* & 3 & + & & + \\
\hline 40 & Sneezing \& snorting ${ }^{*}$ & 3 & + & + & \\
\hline 41 & Stand-offish in stable, unfriendly, pins ears, bites or threatens to bite & 3 & + & & \\
\hline 42 & Tail swishing or wringing („flashing”), particularly when asked to canter. Reluctance to maintain canter & 3 & + & & + \\
\hline 43 & Ear pinning at exercise, threatens to bite other horses that come alongside. Rarely pricks ears (\#9) & 3 & + & & \\
\hline 44 & Lip slapping (noisy flapping of lower lip) & 2 & + & & \\
\hline 45 & Blepharospasm (rapid and often noisy blinking) and/or photophobia* & 2 & + & & \\
\hline 46 & Interfering' with hind hoof (hitting front hoof with hind hoof on same side) & 2 & + & & + \\
\hline 47 & Napping (refusal or reluctance to go forward) & 2 & + & & + \\
\hline 48 & Backing-up to avoid the bit. A habit of reversing rapidly without being asked & 1 & + & & + \\
\hline 49 & Tying-up (exertional rhabdomyolysis) & 1 & + & & + \\
\hline 50 & Refusal to stand still & 1 & + & & + \\
\hline 51 & Unwilling to have a hose played on its head & 1 & + & & \\
\hline 52 & Unwillingness to be clipped around the ears. & 1 & + & & \\
\hline 53 & Breaking out in a sweat even when being bridled & 1 & + & & \\
\hline 54 & Difficult to catch in the paddock & 1 & + & & \\
\hline 55 & Dragging toes of hind feet & 1 & + & & + \\
\hline 56 & Runs wild on the lunge rein and may eventually fall & 1 & + & & + \\
\hline 57 & Explosive coughing at exercise as a post-operative complication of laryn & 1 & + & + & \\
\hline 58 & During arena or paddock exercise, repeatedly heads for the stable when passing by the gate & 1 & + & & + \\
\hline
\end{tabular}

Signs that can be caused by the bit but which were not reported in this survey

59 Inappetence for a day or so after racing or other exercise, resulting from a sore mouth

60 Bleeding from the mouth, as a result of direct trauma from the bit

61 Breakdowns (from premature fatigue, most frequently triggered by shortage of breath $(\# 13,19)$

62 Asphyxia-induced pulmonary edema („bleeding") as a result of upper airway obstruction (\#13, 19)

63 Epiglottal entrapment as a result of open mouth and elevation of the soft palate or DDSP (\#15)

64 Thumps' (synchronous diaphragmatic flutter), e.g. from insufficient drinking on a trail ride (\#38) 
were, on first glance, 58 apparently different expressions of adverse behavior. But although it was useful to document each of these 58 items, it became apparent that line items 5 to 58 inclusive could also be viewed as subsets of one of the first four line items. When the frequency of line items 5 to 58 were reassigned and added to the first four, this had the effect of causing 'fight' and 'flight' to be switched in order of frequency. The actual figures became 'Fear' (122), 'Fight' (84), 'Flight' (79), and 'Facial Neuralgia' (70).

The four major effects of the bit on the behaviour of the horse can be listed as the four $\mathrm{F}^{\prime}$ s. Significantly, all of the 58 effects could be classified under the descriptive term, 'responses to pain.' The text that follows provides notations on some of the line items in Table I.

\section{Fear}

Horses were also described as being anxious, 'jittery,' excitable, and having a tendency to 'explode,' to 'go rubber,' to become 'like jelly' or 'unglued.' The terms 'apprehensive,' 'high-spirited' and 'too spirited' were also used. Nervous horses shied readily and recovered slowly. Some spun round and fled at the slightest provocation. Understandably, riders were often unseated and, using the reins to regain their balance, would inadvertently hit their horses in the mouth. Whatever it was that caused the horse to shy in the first instance (it may or may not have been the bit), the horse now received a second fright from a sharp pain in its mouth, confirming its suspicion that the first 'monster' was indeed scary. Now it had a second reason to flee and the next time it saw the same 'monster' it shied even more readily. The problem became exacerbated. Conversely, with the bitless bridle, the horse is not hurt by the rider tugging momentarily on its head, so it recovers quicker from the fright and is less likely to run out of control.

Memory of past painful experiences with novice riders made certain horses intolerant to children. The child or novice rider lacks an independent seat and, once again, using the reins as straphangers, they bang the horse in its mouth without mercy. Understandably, the horse reacts by bucking, rearing, or bolting.

The expectation of pain sapped a horse's confidence. Apprehensive horses were often labeled as lacking in 'forwardness' or as 'untrustworthy.' At fences, such a horse often shied, ran out, or refused, a cause of serious accidents and fatalities On the racetrack, many bitted horses were regarded as 'difficult' rides and others were known as inveterate pullers or bolters. One filly was described as "a lunatic and an outlaw." This same filly reared-up constantly in the starting gate and had put a number of riders in hospital. The trainer reported that the horse "terrorized all about her" and was always covered in sweat on return from work. Once the bit was removed, a $110 \mathrm{lb}$ boy rode the same horse without incident. Another horse that would 'lose its mind' was further described by its trainer as "spooky, hot, spirited, dangerous, hell-crazy, blown-mind, and untrainable."

In the show jumping ring, nervous horses were likely to rush their fences and, on landing after a jump, might stumble, fall or flee.
Flight

Variations on this theme included horses that showed a reluctance, hesitation, or resistance in responding to the cue for 'halt' or 'half-halt.' Others were unwilling to be rated at the canter, or refused to canter at one steady speed. Alternatively, they bucked at the canter when checked. 'Rein-backs' were accomplished only with resistance. The fact that so many confirmed bolters became compliant and easy to control when the bit was removed supports the view of many a horseman that when faced with this problem riders should change to a bit that is less rather than more severe. Obviously, the ultimate of 'less' is no bit at all.

\section{Fight}

Riders reported that their horses were constantly "fighting the bit" and showing an inclination to 'argue' about every aid. Some horses were slow to obey a downward transition. Others commented on 'unwillingness, unhappiness, and stubbornness.' Riders described such horses as being 'opinionated' or 'bossy' and commented that they could not be controlled without them becoming hot, resentful, and sweaty. One owner was advised that her nervous, strong and almost uncontrollable horse was "not worth keeping." When trying to buy yet another bit, a tack shop proprietor told her "Don't sound like a bit is gonna solve your problem and we don't sell guns."

\section{Facial neuralgia}

Some bitted horses took a long time to 'settle down.' They would, for example, shake their heads constantly for the first five or six miles of a trail ride. Others were described as going through a 20-minute period of 'I'm in charge' behaviour. Evasion of rein contact by head tossing and ducking away from the bit was frequently reported. One horse would "walk into a wall" during a headshaking frenzy. Another would, apparently by choice, run into another horse before stopping. Others threw their heads up when moving from a trot to a canter. Some show jumpers threw up their heads when checked before a jump. This resulted in a lack of focus, accidents and poor jumping performances. Some horses stalled at the jump ('refused').

\section{6}

In the stable, many a horse panicked at the very sight or sound of a bit. They backed away from the handler, put their head in the air and 'grew tall.' Others clenched their teeth and refused to open their mouths ('balked at the bit'). The process of bridling was especially difficult in winter, when horses resented the touch of cold steel in their mouth. Some horses broke out in a sweat before they even started exercising. The struggle over bridling resulted in long delays to the task of tacking-up and high stress levels in both rider and horse. Horses often became so shy that they could no longer be handled anywhere around their mouth. Others appeared to become shy when handled around the ears in order to draw the bit into the mouth.

One horse refused to take the bit for the first time on day four of a seven-day trail ride and consistently balked at the bit thereafter. One young Thoroughbred in race training required two men to hold her when she was tacked-up. Another Thoroughbred that had reared up in the starting gate, refused to allow a bridle on its head subsequently, suggesting that bit pain might have been the cause of the rearing. Conversely, 
these same horses, when they became accustomed to the bitless bridle, often developed the endearing habit of dipping their heads in to the bridle without being asked.

Some horses were difficult to handle at the time a bitted bridle was removed. Episodes of head flinging would occur, as horses expressed fear of the bit rattling against their incisor teeth.

\section{7}

Horses that were over-extended at the poll and held their head high ('above the bit') were often described as having also put the bit 'between their teeth.' This may be literally true or it may be that horses so described did not actually clamp the bit between their second premolars, but rather placed the bit against the rostral edge of these teeth, where it caused less pain than it did when pressing on the diastema. Alternatively, some horses held their heads low and in extension so that similar relief from the bit could be obtained.

8

On first going out on a trail, one bitted horse was always reluctant to leave its home paddock, moving in a zigzag fashion rather than a straight line.

\section{9}

Horses expressed their failure to enjoy work by pinning back their ears for much or even all of the exercise period. Others showed a wildness of eye, or developed tail 'flashing,' 'winding' or 'wringing.' (Table I: \# 42). A reluctance to canter was another expression of unhappiness. Horses showed a general inattentiveness to the aids and were unresponsive or slow to respond. Loss of alertness during a trail ride was reported, with the development of a 'hangdog', 'dull', 'hectored', or 'unhappy' expression. This occurred, in particular, when there were no other horses in sight. With nothing to distract it, the horse was presumed to be focusing on the pain in its mouth. Such horses were often thought by their riders to be 'lacking in energy.' This may, of course, be true, as few things will sap our energy quicker than constant pain. To give an example analogous to the sort of pain that the bit must produce, we know how we feel with toothache. The mandibular branch of cranial nerve $V$ supplies the bars of the mouth, gum, tongue, lips and teeth, with sensory perception and the modalities of pain and temperature (including itch and tickle). Pain from constant bone ache in the lower jaw will probably be similar to the pain of an intense toothache. The bit lies on the diastema immediately dorsal to the mental foramen. Another example of lack of finesse in communication was the inability or refusal of some bitted horses to lead on the correct leg, or to change leads.

10

Tenseness in the neck and back resulted in a short choppy stride ('stiff action') or an uncoordinated, clumsy, gait. In some cases, this led to a mistaken diagnosis of equine protozoal myeloencephalitis.

\section{2}

'Leaning on the bit' and being 'heavy on the forehand' were alternative descriptive terms for 'imbalance' and 'lack of selfcarriage.' No 'leaning' would be possible unless the tongue was also 'over the bit', as otherwise there would be nothing for the horse to lean on.

\section{3}

If airway obstruction was intense, this was accompanied by laryngeal fremitus detectable on palpation immediately after exercise (Cook 2002).

17

A lack of any spirit of cooperation or sense of partnership between horse and rider was frequently reported. The bit was found to be responsible for an "absence of trust." Every ride involved "getting into a fight" with the horse. Inevitably, this sometimes degenerated into "yelling and cursing matches."

\section{8}

A lack of energy and absence of 'drive' had often been previously attributed to inherent laziness when, in reality it was associated with bit-induced pain. One pony that refused to trot was accused of being 'ring sour.' Another pony was always considered to be "looking for excuses not to work." Horses were also unfairly accused of being 'barn sour.' Such a horse became 'pesky' or 'cranky' after a little exercise and was no longer willing to work, being inclined to head for home. Others developed behaviour that riders interpreted as a message to the effect that "Its time you got off." A few horses became aggressive and developed a positively dangerous attitude to work. Some became unrideable. Conversely, instead of becoming aggressive, horses of certain temperaments reacted to pain by becoming depressed and subdued. Spurs were thought necessary to persuade them to move from a trot to a canter. At the end of a ride, these horses were sweatier than others.

20

Relentless slow trotting ('jigging' or 'rushing') when required to walk was sometimes accompanied by 'side-passing.'

\section{1}

A constant chomping, champing and general fussing with the mouth resulted in horses failing to 'listen' to the rider.

\section{7}

Because of increasing resentment to the bit, progress with schooling was often slow, unnecessarily prolonged, or even non-existent. Problems seemed particularly likely to occur when schooling was commenced early in a horse's life during the 'teething' period. Conformation defects such as parrot and bulldog mouth were reported to make horses especially unreceptive to being bitted. Horses that owners believed to have "shallow arches to the roof of their mouth" and "large fleshy tongues" were said to be more difficult to bit.

\section{8}

Some horses reared as soon as the rider gathered up the reins and prepared to put a foot in the stirrup.

29

With a bit in the mouth, recovery from a stumble, as from shying, was often slow.

37

A sudden diving movement of the head often pulled the rider out of the saddle. This stretching out of the neck was someti- 
mes accompanied by jaw movements, sideways and vertical, like a modified yawn. 'Rooting' was particularly likely to occur when bit pressure was increased. The evasion probably resulted in the bit being placed against the rostral edge of the second premolars.

Conversely, horses that after a period of collected work were deliberately put on a loose rein in order to give them a chance to put their heads down and stretch their necks, refused to do so. In hindsight, owners attributed this reluctance to the possibility that horses were frightened to put their heads down for fear of triggering painful bit contact.

33

During mounting, horses would move off before the rider was properly in the saddle. Such episodes led to riders being injured and horses getting loose.

When ridden, hypersensitive responses to the aids often resulted in the horse rushing forward or backward, running away, or bolting. Such horses sometimes exhibited a response to the aids that was opposite to that requested. Even the slightest pressure on the rein, for example, would result in a panic attack, followed by high-speed flight. With bits in their mouths, some horses were regarded as dangerous to ride. Moderate rein pressure failed to persuade such horses to relax and work calmly, yet a 'death-grip' on the reins provoked panic attacks, and a loose rein amounted to no control at all.

Once again, the opposite reactions were also reported (Table I: \# 18)

38

Failure or disinclination to drink during trail rides, led to dehydration and loss of 'condition.' The presence of a bit breaks the seal of the lips and renders it difficult for a horse to generate the necessary intra-oral vacuum for drawing fluid into its mouth. This, together with oral pain, may result in the intake of water being inadequate. Some horses refused to drink on a trail ride (Table I: \#64).

41

Horses were described as being suspicious or resentful in their attitude towards anyone approaching in the stable. Such horses avoided eye contact and were described as developing a nervous, 'cat-like' attitude.

42

Gaited horses were reported to not stay in gait.

46

Some horses 'interfered' as a corollary to lugging in or out (\#8).

54

Failure to show eagerness at the prospect of exercise (the horse equivalent of a dog failing to get excited at the prospect of a walk). One pasture-boarded horse that had to be brought in from the paddock prior to riding was difficult to catch (After the bitless bridle was introduced, this same horse came galloping to the gate).
58

Horses exhibited a wish to return to the stable at the first opportunity and as quickly as possible (bolting towards home).

\section{Survey of skulls}

This survey provided tangible evidence of the source of the pain that the bit inflicts. From 65 adult Equus Caballus skulls (five years old or older), 49 (75\%) were found to have bilateral exostoses on the dorsal surface of the diastema (Cook 2002). The position of these bone spurs, in an area devoid of tendinous or ligamentous insertions, made it apparent that they were caused by the bit. A survey of 35 adult zebra skulls (Equus Burchelli and Equus Grevyi) revealed no such exostoses and neither were any found in Equus Caballus skulls from known feral locations.

\section{Discussion}

The report evidence may be criticized on the grounds that, apart from those occasions when the behavior changes have been witnessed by the author at the time or reviewed on video, it is predominantly hearsay evidence. But such evidence is no different from the sort of evidence collected in many retrospective and prospective studies. Its value is defended for a number of reasons.

Firstly, it represents the first-hand experience of riders about their own horses. Such people have had the opportunity to become familiar, often all too familiar, with the characters, idiosyncrasies and behaviour patterns of their horses, generally over a period of many years prior to switching to the new bridle (Many riders who had assumed that their horse's characters were inborn and unchangeable were pleased to discover, when the bit was removed, that this was not so and that their horses character underwent a remarkable change for the better). Any changes in behaviour are matters of importance to riders and will be immediately noticed, analyzed, and scrutinized for their validity and repeatability. As a class, riders can be relied upon to be highly critical of any newly-designed equipment, especially an item such as a bridle that is so critical to the whole of equitation. Riders themselves had nothing to gain from volunteering their reports.

Secondly, each horse acted as its own control. The rider had used the same horse, with and without a bit, for the same purpose, under similar conditions, and within a short time frame. The improvement in behaviour following removal of the bit was so immediate and so remarkable that there was no doubt with regard to what had brought it about. Many reports were submitted after the very first trial.

Finally, in a number of instances, owners had carried out a double check by re-instating the bit for a further trial period, only to see the adverse behavioural signs return.

It is interesting to note not only the wide spectrum of signs but also their range of expression. For example, a spirited horse may respond to the pain of the bit by bolting, whereas another of a more phlegmatic temperament may simply become 
sluggish and get accused of laziness. Some bitted horses held their heads too low, whereas others held their heads too high. Some were over-extended at the poll while others were overflexed. It is not claimed that the bit is the only cause of these 58 behavioural signs, though it is undoubtedly a major cause of most and the only cause of many. This is attested to by the frequency with which removal of the bit eliminated these items of adverse behaviour in the riding horse. Both riders and the author have been surprised to discover how often some problem that was previously considered intractable, has responded to the simple expedient of dispensing with the bit.

The adverse behaviour patterns resulting from bit-induced pain can also be classified systematically as follows:

Interference with attitude to exercise (nervous system)

Interference with breathing (respiratory system)

Interference with striding (musculoskeletal system)

Clearly, the causal factor is pain, for pain is the factor common to all the signs listed in Table I. As horses don't scream, pain is expressed through body language or by some change of function (breathing or striding). As breathing and striding are synchronized (Cook 1965) at the trot, canter, and gallop, any interference with breathing will also interfere with striding, and vice-versa. This linkage means that whenever one of these effects is triggered by pain, the other effect will also be present to some degree. In Table I both effects are marked as positive only for those instances where pain appears to stimulate both effects to a high degree.

The survey provided, at long last, a convincing explanation for the cause of the headshaking syndrome. Removal of the bit eliminated headshaking in 66 horses (Table I: \#4). That the bit may be regarded not only as a cause but also as the most common cause of headshaking is indicated by the fact that headshaking did not persist in any one of this extensive series of affected horses. The evidence supports an earlier opinion (Cook 1998).

Until now, the numerous etiological hypotheses for the headshaking syndrome have been reminiscent of the poem about the six blind men trying to define the characteristics of an elephant ("The Blind Men and the Elephant" by John G. Saxe). Amongst others, the theories have included allergic rhinitis (Cook 1979a, 1979b, 1980a, Lane and Mair 1987), vasomotor rhinitis (Cook 1980b, Lane and Mair 1987, McGorum and Dixon 1990), photophobia (Cook 1980a, Madigan and Bell 1998), dental pain (Cook 1980b), upper airway obstruction (Cook 1992), equine protozoal myeloencephalitis (Moore et al 1997), and neuralgia of the posterior ethmoi$\mathrm{dal} /$ nasal branch of the ophthalmic division of the trigeminal nerve (Newton et al 2000). Now it seems that all the clinical signs comprising the headshaking syndrome (see Table I: asterisked items \#4, 36, 39, 40, and 45) can be more parsimoniously explained as being consistent with bit-induced trigeminal neuralgia.

A unifying hypothesis can be put forward to the effect that pain sensations are referred centrally from the diastema of the mandible via the mandibular branch of the trigeminal nerve (cranial nerve V) (Incidentally, this hypothesis suggests an explanation for the greater prevalence of headshaking in males rather than females (Lane and Mair 1987). The root of the canine tooth lies close to the portion of the diastema upon which the bit presses. The presence of this root and its nerve supply would explain the increased sensitivity of males.

Pain sensations are also thought to spread rostrally by a process of 'talk-back' from the level of the trigeminal ganglion down the other two branches of the trigeminal, the maxillary and ophthalmic branches. Acute pain referred directly to the brain accounts, I propose, for the uncontrollable head tossing, whereas pain, itching or tingling sensations transmitted by the maxillary nerve to the region of the muzzle would explain the muzzle rubbing, sneezing, and snorting. Similar feedback via the ophthalmic nerve can be invoked to explain the photophobia and blepharospasm. Such a hypothesis withstands the test of falsification, as removal of the proposed cause (the bit) proves to be a treatment that, in the author's experience, is infinitely more effective than any others that he has tried.

Another result of the survey has been to demonstrate that laryngeal stridor ('roaring' and 'thickness of wind') and laryngeal fremitus are clinical signs compatible with upper airway obstruction caused by bit-induced elevation of the soft palate (Cook 2002). In future, this needs to be considered as a differential diagnosis for recurrent laryngeal neuropathy, a disease that has previously been considered the most likely source of these signs (Cook 1988). A corollary to this is the realization that dorsal displacement of the soft palate is yet another problem of previously unknown cause for which the bit is responsible (Cook 2002).

A number of horses in the survey had already undergone unsuccessful treatment for Equine Protozoal Myeloencephalitis (EPM). As the correlation between cause and effect of symptoms and disease in the case of EPM is difficult, it is possible that some horses showing signs such as incoordination (Table I: \# 14) were mistaken for EPM.

Drivers depend even more than riders on effective communication with their horse's head, as communication through the use of seat, legs and balance is not an option. For this reason, problems arising from use of the bit would seem to be even more relevant to driving than they are to riding. The author anticipates that the bit will be found to have an even more harmful effect on the behaviour of the carriage or harness horse than it does on the riding horse. In the future, as more drivers take to bitless driving, it will be interesting to test this prediction. It would appear that whenever any one of the behavioural signs listed in Table 1 is encountered, removal of the bit should be considered as an early line of approach to both diagnosis and treatment. By dispensing with the bit we can improve the horse's welfare, enhance its performance and, at the same time, render equitation simpler, safer, and more enjoyable for man and horse.

\section{Acknowledgements}

Funded in part by the Aldus C. Higgins Foundation and the M.P.D. Higgins Foundation.

The author is deeply indebted to the equestrians for their written reports. Valuable help was also received from the staff of the Smithsonian Institution (The Natural History Museum and 
The Museum of American History), Washington DC; the Museum of Comparative Zoology, Harvard University, Cambridge, MA; and The Field Museum, Chicago, IL.

The author declares that he is the chairman of The Bitless Bridle Inc.

Manufacturer's address: The Bitless Bridle Inc. 2020, South Queen Street, York, PA, 17403-4829 USA

\section{Literature}

Cook W R (1965): The diagnosis of respiratory unsoundness in the horse. Vet. Rec. 77, 516-528

Cook W R (1979a): Headshaking in the horse, Part I: Description of the Syndrome. Eq. Pract 1, 9-17

Cook W R (1979b: Headshaking in the horse, Part II: History and management tests. Eq. Pract 1, 36-39

Cook W.R (1980a): Headshaking in the horse, Part III: Diagnostic tests. Eq. Pract 2, 31-40

Cook W R (1980b): Headshaking in the horse, Part IV: Special diagnostic features. Eq. Pract 2, 7-15

Cook W R (1988): Recent observations on recurrent laryngeal neuropathy in the horse: Applications to practice. Proc Am. Ass. equine Practnrs 34, 427-478.

Cook W R (1992): Headshaking in horses: An afterword. Comp. Cont. Educ. Pract. Vet. 14, 1369-1372

Cook W R (1998): Use of the bit in horses. Vet. Rec. 142, 200

Cook W R (1999): Pathophysiology of Bit Control in the Horse. J. Equine Vet. Sci. 19, 196-204
Cook W R (2000):. A solution to respiratory and other problems caused by the bit. Pferdeheilkunde, 16, 333-351

Cook W R (2002): Bit-Induced Asphyxia: Elevation and Dorsal Displacement of the Soft Palate at Exercise. J. Equine Vet. Sci. 20, 7-14

Madigan J E and Bell S A (1998): Characterisation of headshaking syndrome - 31 cases. Equine vet. J. Suppl. 27, 28-29

Manning A (1979): An Introduction to Animal Behaviour. Third edition. Edward Arnold Ltd. United Kingdom.

McGorum B C and Dixon P.M (1990:). Vasomotor rhinitis with headshaking in a pony. Equine vet. J. 22, 220-222

Moore LA, Johnson P. J, Messer N, Kline K L, Crump L M, and Knibbe J R (1997): Management of headshaking in three horses by treatment for protozoal myeloencephalitis. Vet. Rec. 141, 264-267

Newton S A, Knottenbelt D C, and Eldridge PR (2000): Headshaking in horses: possible aetiopathogenesis suggested by the results of diagnostic tests and several treatment regimes used in 20 cases. Equine vet. J. 32, 208-216

Lane J G and Mair T S (1987): Observations on Headshaking in the horse. Equine Vet. J. 19, 331-336

Robert W. Cook, MRCVS, Phd 206, Birch Run Road

Chestertown, MD 21620 USA.

Tel/Fax: (410) 7789005

E-mail:drwrcook@aol.com 